\title{
Methane emission, metabolism, and performance of Holstein dairy cows with low, medium, and high lymphocyte proliferation during transition
}

\author{
S. Meese, ${ }^{1,2} \odot$ S. E. Ulbrich, ${ }^{3}$ H. Bollwein, ${ }^{4}$ R. Bruckmaier, ${ }^{5} \odot$ O. Wellnitz, ${ }^{5} \odot$ M. Kreuzer, ${ }^{1} \odot$ M. Röntgen, ${ }^{6} \odot$ \\ U. Gimsa, ${ }^{7}$ and A. Schwarm ${ }^{1,8 *}$ (1) \\ ${ }^{1}$ ETH Zurich, Animal Nutrition, Institute of Agricultural Sciences, 8092 Zurich, Switzerland \\ ${ }^{2}$ AgroVet-Strickhof, 8315 Lindau, Switzerland \\ ${ }^{3}$ ETH Zurich, Animal Physiology, Institute of Agricultural Sciences, 8092 Zurich, Switzerland \\ ${ }^{4}$ Clinic of Reproductive Medicine, Vetsuisse Faculty, University of Zurich, 8057 Zurich, Switzerland \\ ${ }^{5}$ Veterinary Physiology, Vetsuisse Faculty, University of Berne, 3001 Berne, Switzerland \\ ${ }^{6}$ Institute of Muscle Biology and Growth, Leibniz Institute for Farm Animal Biology, 18196 Dummerstorf, Germany \\ ${ }^{7}$ Institute of Behavioural Physiology, Leibniz Institute for Farm Animal Biology, 18196 Dummerstorf, Germany \\ ${ }^{8}$ Department of Animal and Aquacultural Sciences, Norwegian University of Life Sciences, 1432 Ås, Norway
}

\begin{abstract}
This study aimed to identify interactions between state of lactation (dry or early lactating) and immune responder group (low, medium, or high) for energy metabolism traits as well as metabolic and immunological traits in dairy cows. In early lactation, when the energy priority of cows shifts toward the mammary gland, the energy available to be partitioned toward the immune system may differ among individuals. The equilibrium between energy supply from feed, digestion, and body reserve mobilization and energy expenditure with milk, immune system, methane, and heat production is delicate in this stage. Seventeen Holstein cows entering their second to fifth lactation were kept under comparable feeding, housing, and management conditions and were studied from $14 \pm 6 \mathrm{~d}$ before calving to $11 \pm$ $3 \mathrm{~d}$ after calving. Feed intake, milk yield, body condition, blood metabolites, and cortisol as well as gaseous exchange in respiration chambers were measured. The latter was used to quantify methane emission and to calculate resting metabolic rate and heat production. Subsets of blood leukocytes and peripheral blood mononuclear cells (PBMC) were monitored. Activation and proliferation of the PBMC in response to the mitogen phytohemagglutinin ante- and postpartum were assessed using the oxygen consumption rate (24-h cell culture assay) and the 3-(4,5-dimethylthiazol-2-yl)-2,5 diphenyl tetrazolium bromide (MTT) assay (72-h cell culture assay). Cows were classified based on the in vitro proliferative response of the PBMC measured postpartum in low $(\mathrm{n}=6)$, medium $(\mathrm{n}=5)$, and high
\end{abstract}

Received September 12, 2019

Accepted January 2, 2020.

*Corresponding author: angela.schwarm@nmbu.no $(\mathrm{n}=6)$ responders. We found no interaction of state of lactation with responder group for feed intake, milk yield, efficiency, metabolic traits, and immune cell activation ante- and postpartum. However, after calving, low-responder cows produced less methane per unit of body weight and per unit of energy-corrected milk compared with the other cows. This might be indicative of a low rumen fermentation intensity. Low responders might therefore suffer from a lower availability of digestible energy in early lactation and not be able to sustain the shift from immune cell activation to proliferation. If so, the selection of environmentally friendly low-methane emitters could promote phenotypes with a compromised immune response in the critical early lactation.

Key words: immune system, lymphocyte activation, mitogen, ruminant

\section{INTRODUCTION}

In early lactation, the proliferative response of leukocytes can largely differ among dairy cows. This is mostly related to differences in metabolic and endocrine adaptations accomplished during transition, when the partitioning of energy and nutrients prioritizes the mammary gland. In addition, a mobilization of body reserves compensates for the faster increase of energy output through milk production than energy input by feed uptake (Gross et al., 2011). Thus, nutritional status is directly linked to the capability of the immune system (Mallard et al., 1998; Sordillo, 2016). The main factor contributing to energy supply is ruminal digestion. Cows with a higher energy loss from ruminal methane emissions might lack energy to support the immune system. Alternatively, higher methane emissions could be indicative of a greater ruminal fermentation activity and thus nutrient digestibility of such cows. 
The energy consumed by activated leukocytes was found to account for $25 \%$ of the basal metabolic rate (Straub et al., 2010). Therefore, cows with an energy deficiency, which can support immunological maintenance but not activation, might also display smaller resting metabolic rates (RMR) and energy expenditures (heat production; HP), both indicators of lower metabolic energy turnover.

The effect of state of lactation on immunological traits has been reported repeatedly. For example, in vitro activation and proliferation of peripheral blood mononuclear cells (PBMC) was observed to be lower (Kashiwazaki et al., 1985; Schwarm et al., 2013), higher (Burton et al., 1993), or the same (Lacetera et al., 2005; Dang et al., 2013) in early-lactating cows compared with dry cows. The PBMC consist predominantly of $\mathrm{T}$ and B lymphocytes as well as some monocytes. The immune response to a mitogen in vitro is assumed to reflect the response to an antigen in vivo. Consequently, the risk for infectious diseases is considered to be higher when PBMC activation or proliferation are low. The immune response is modulated by metabolites in the extracellular fluid, such as nonesterified fatty acids (NEFA) and BHB. These metabolites, which frequently occur at higher concentrations in plasma in early lactation due to body reserve mobilization, can modulate PBMC proliferation (Lacetera et al., 2004; Wang et al., 2018) and acute inflammation (Zarrin et al., 2014).

Upon stimulation, immune cells require glucose for their metabolism, and extrinsic signals are needed to utilize such nutrients to maintain metabolic activity (Rathmell et al., 2000). This explains why the level of PBMC activation is related to plasma glucose concentration (Jones et al., 2005; Schwarm et al., 2013) and thus de novo synthesis of glucose from nutrients absorbed from the gut rather than to lipids mobilized from body reserves. Upon stimulation, PBMC enter the cell cycle by shifting from the quiescent $G_{0}$ phase to the activation phase, the $\mathrm{G}_{1}$ phase. In an unfavorable extracellular environment, cells do not proceed from the $G_{1}$ phase to the DNA synthesis phase and the cell cycle is aborted. This phenomenon is most likely the cause of a reduced PBMC proliferation.

Indicator traits of adaptive immunity can help identify cows with a low or high ability to mount an immune response (Catalani et al., 2013). Stoop et al. (2016) and Amadori et al. (2018) classified cows as low, medium, and high immune responders at one state of lactation. No difference in production traits among low, medium, and high responders was observed by Stoop et al. (2016). No energy metabolism traits were reported by these authors.

The present study aimed to identify interactions of the degree of PBMC proliferation with state of lac- tation (dry or early lactating) for energy metabolism traits as well as metabolic and immunological traits in dairy cows. We hypothesized an interaction of state of lactation (before or after calving) with animal group (low, medium, or high responders) for the aforementioned traits.

\section{MATERIALS AND METHODS}

\section{Experimental Design}

The experimental protocol complied with the Swiss legislation for animal welfare and was approved by the Committee on Animal Experimentation of the Cantonal Veterinary Office Zurich (license no. 06/2014). Seventeen Holstein cows in transition to their second to fifth lactation were selected from the AgroVet-Strickhof herd (Eschikon, Lindau, Switzerland). The dry period was initiated 8 to $10 \mathrm{wk}$ before expected calving. Cows were studied from (mean $\pm \mathrm{SD}$ ) $14 \pm 6 \mathrm{~d}$ before calving to $11 \pm 3 \mathrm{~d}$ after actual calving. Based on the in vitro proliferative response of their PBMC after calving, cows were grouped into low $[\mathrm{n}=6$; proliferation index (PI) of 1.3-1.8], medium $(\mathrm{n}=5$; PI of $2.0-2.4)$, and high $(\mathrm{n}=6$; PI of $2.6-4.3)$ responders (see Figure $1 \mathrm{~A}$, postpartum). The proportion of low and high responders was defined as $1 \mathrm{SE}$ below and above the mean, respectively. The average lactation numbers of the low, medium, and high groups were $2.8 \pm 0.40,3.0$ \pm 0.45 , and $3.0 \pm 0.52$, respectively. The experiment was conducted in subsequent runs of 1 to 2 cows each because only 2 respiration chambers were available. The procedures carried out lasted for $6 \mathrm{~d}$ antepartum and $6 \mathrm{~d}$ postpartum for each cow. All cows were clinically healthy at these times. They calved normally in proximity to the anticipated calving date. One cow in the fourth lactation from the medium-responder group had a twin birth.

\section{Management of the Cows}

The cows remained in their usual tiestalls for most of the experiment except for 2 stays of $2 \mathrm{~d}$ in respiration chambers, where they were tied as well. During the dry period, the cows received a mixed forage ration consisting of chaffed wheat straw, grass silage, corn silage, mineral-vitamin pellets, and extra hay (Table 1). During lactation, the mixed ration consisted of corn silage, grass silage, concentrate, hay, and $\mathrm{NaCl}$, with part of the corn silage being replaced by sugar beet pulp in winter. In cases where milk yield exceeded $32 \mathrm{~kg} / \mathrm{d}$, an energy concentrate was offered on top at $1 \mathrm{~kg} / 2 \mathrm{~kg}$ of milk in 4 portions/d. Otherwise, feed was provided at 0400 and $1415 \mathrm{~h}$. The cows had 
A

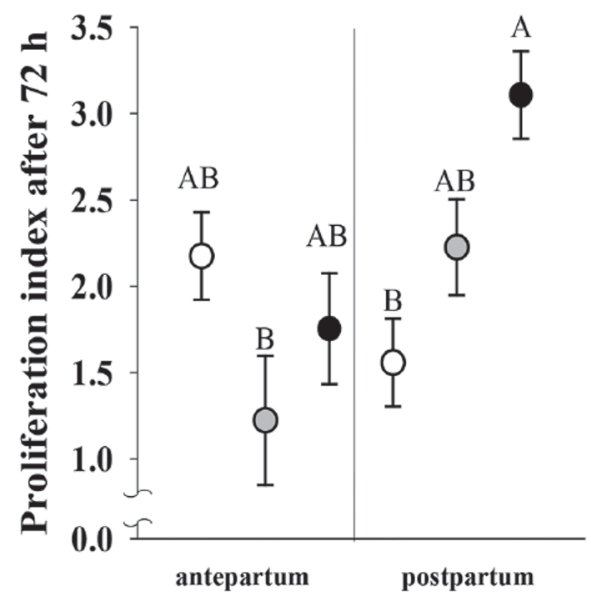

C

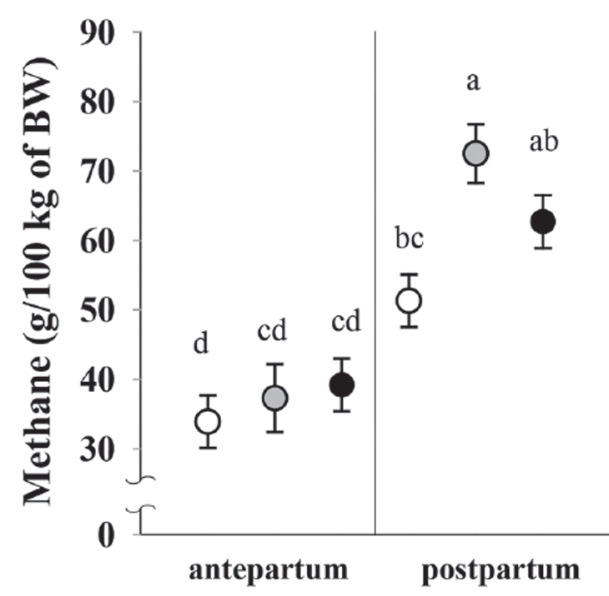

E

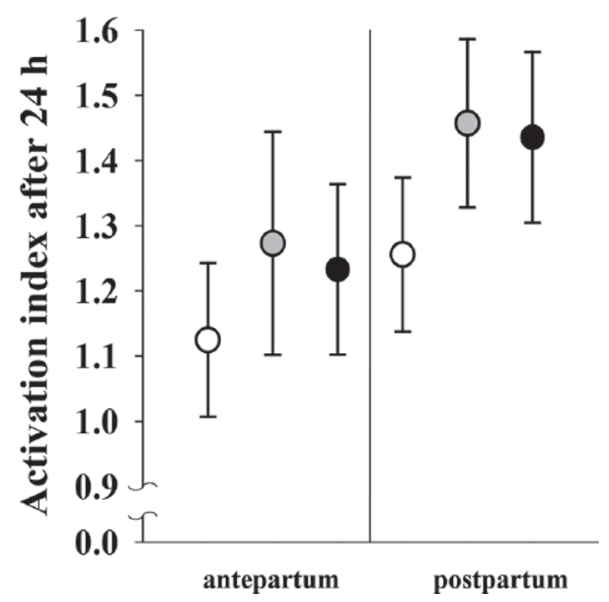

B

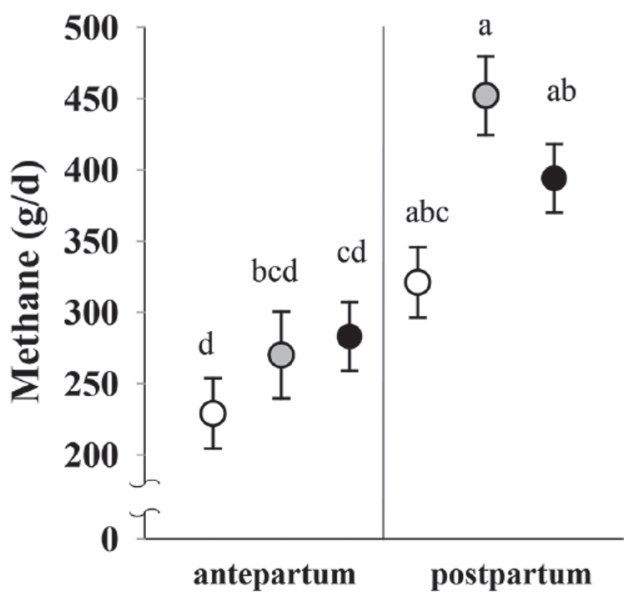

$\mathrm{D}$

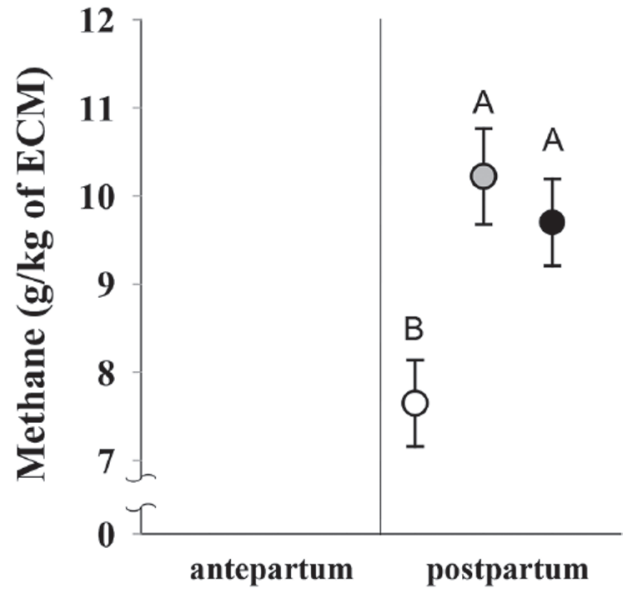

Figure 1. (A) Proliferation index (PI) of peripheral blood mononuclear cells (PBMC); methane emissions (B) per day, (C) per unit of BW, and (D) per unit of ECM; and (E) activation index of PBMC on d $14 \pm 6$ before calving (antepartum) and $11 \pm 4$ DIM (postpartum) in cows with low (white circles), medium (gray circles), and high (black circles) PI after calving. The activation index is the ratio of oxygen consumed by stimulated and nonstimulated PBMC after $24 \mathrm{~h}$ of incubation. The PI is the ratio of 3-(4.5-dimethylthiazol-2-yl)-2.5 diphenyl tetrazolium bromide-reducing activity of stimulated and nonstimulated PBMC after $72 \mathrm{~h}$ of incubation. Data are presented as LSM \pm SE. Effects were for $\mathrm{PI}_{\text {(time, group } \times \text { time) }}(P<0.05)$ and for $\mathrm{PI}_{\text {(group) }}(P<0.10)$. Observed effects were for methane emissions per day and per unit of $\mathrm{BW}$ (group, group $\times$ time) $(P<0.10)$, for methane emissions per day and per unit of $\mathrm{BW}_{(\text {time) }}(P<0.05)$, and for methane emissions per unit of $\mathrm{ECM}_{\text {(group })}(P<0.05)$. No effects $(P>0.10)$ were found for activation index. Means without common letters $(\mathrm{A}, \mathrm{B}$ at $P<0.05$ and a-d at $P<0.10)$ differ. 
Table 1. Nutrient content (mean $\pm \mathrm{SD}$ ) of the feed components and the respective amounts offered during the dry and lactation periods

\begin{tabular}{|c|c|c|c|c|c|}
\hline \multirow[b]{2}{*}{ Item } & \multicolumn{2}{|c|}{ Dry period } & \multicolumn{3}{|c|}{ Early-lactation period } \\
\hline & Forage $\operatorname{mix}^{1,2}$ & Extra hay & $\begin{array}{c}\text { Forage protein } \\
\text { concentrate- } \\
\text { mineral mix }\end{array}$ & $\begin{array}{c}\text { Energy } \\
\text { concentrate }^{4}\end{array}$ & Extra hay \\
\hline No. of samples & 30 & 30 & 34 & 1 & 22 \\
\hline DM (\%) & $35.0 \pm 4.1$ & $89.6 \pm 4.1$ & $42.3 \pm 3.4$ & 93.0 & $88.9 \pm 2.9$ \\
\hline \multicolumn{6}{|l|}{ Nutrient (\% of DM) } \\
\hline $\mathrm{CP}$ & $8.52 \pm 0.96$ & $6.43 \pm 0.96$ & $13.78 \pm 1.71$ & 24.23 & $13.80 \pm 3.40$ \\
\hline NDF & $55.9 \pm 4.0$ & $66.3 \pm 2.9$ & $42.8 \pm 1.9$ & 21.4 & $57.4 \pm 1.5$ \\
\hline $\mathrm{ADF}$ & $36.5 \pm 2.8$ & $41.5 \pm 1.7$ & $27.7 \pm 1.6$ & 8.5 & $33.3 \pm 1.4$ \\
\hline ADL & $5.52 \pm 1.08$ & $7.49 \pm 0.94$ & $4.40 \pm 0.67$ & 3.50 & $5.46 \pm 0.56$ \\
\hline Ether extract & $2.39 \pm 0.33$ & $1.65 \pm 0.96$ & $2.94 \pm 0.26$ & 6.88 & $1.77 \pm 0.33$ \\
\hline Gross energy (MJ $/ \mathrm{kg}$ of DM) & $18.3 \pm 0.3$ & $18.1 \pm 0.1$ & $18.4 \pm 0.2$ & 17.9 & $17.8 \pm 0.9$ \\
\hline Average amount offered $(\mathrm{kg}$ of $\mathrm{DM} / \mathrm{d})$ & $10.56 \pm 1.47$ & $2.84 \pm 1.53$ & $19.44 \pm 3.33$ & $3.23 \pm 0.82$ & $1.05 \pm 0.64$ \\
\hline
\end{tabular}

${ }^{1}$ Comprised (DM basis) chaffed wheat straw, $40 \%$; grass silage, $35 \%$; and corn silage, $25 \%$.

${ }^{2}$ An extra mineral-vitamin supplement (100 g/d per cow; Kroni Locher, Altstätten, Switzerland) that comprised (per kg) Ca, 120 g; Mg, 60 g; $\mathrm{Na}, 30 \mathrm{~g}$; Zn, 440 mg; Mn, 130 mg; Se, 4 mg; Fe, 100 mg; I, 2 mg; Co, 0.7 mg; vitamin A, 20,000 IU; vitamin D $, 2,000$ IU; and vitamin E, 50 mg. ${ }^{3}$ Comprised (DM basis), on average, summer and winter diet (DM basis) of corn silage, 49.5\%; grass silage, 28.2\%; concentrate, $12.5 \%$; hay, 9.4\%; and $\mathrm{NaCl}, 0.4 \%$. During the winter period, $11 \%$ of corn silage was replaced with sugar beet pulp. The concentrate (no. 50109, Getreidesammelstelle, Thalheim, Switzerland) comprised (DM basis) rapeseed cake, 50\%; soybean meal, 17\%; corn gluten, 15\%; wheat, 13\%; dicalcium phosphate dehydrate, $3 \%$; and limestone, $2 \%$. Mineral content (per kg): Ca, $17.8 \mathrm{~g} ; \mathrm{P}, 13.2 \mathrm{~g}$; and $\mathrm{Mg}, 3.35 \mathrm{~g}$.

${ }^{4}$ The energy concentrate (163 Extra MegaDigest, UFA, St. Margrethen, Switzerland) comprised corn, soybean meal, wheat, distillers grains, rapeseed cake, corn gluten, wheat starch, mill by-product mix, feed-grade rice, feed-grade fatty acids, molasses, minerals, dextrose, and wheat bran. Mineral and vitamin content (per kg): P, 50 g; Ca, 7.5 g; Mg, 3.0 g; Na, 1.5 g; Zn, 100 mg; Mn, 50 mg; Fe, 30 mg; Cu, 10 mg; I, 1 mg; Co, $0.4 \mathrm{mg}$; Se, $0.15 \mathrm{mg}$; vitamin A, 15,000 IU; vitamin $\mathrm{D}_{3}, 2,250 \mathrm{IU}$; vitamin E, $15 \mathrm{IU}$; and niacin, $1 \mathrm{~g}$.

permanent access to water. Milking started at 0415 and 1600 h. Mastitis occurred in 1 low-responder cow in fourth lactation at 3 to 5 DIM, and metritis occurred in 1 high-responder cow in second lactation at 10 to 13 DIM. Sampling dates were shifted to after the diseases were cured. Data from these 2 cows were in the range of the other data; therefore, they were not excluded from the data set.

\section{Collection of Data and Sampling}

Individual feed intake was recorded by weighing the total amounts offered and leftovers for $6 \mathrm{~d}$ ( $4 \mathrm{~d}$ in the tiestall followed by $2 \mathrm{~d}$ in the respiration chamber). The mixed dry-off and lactation diets were sampled twice per week over the experimental period. Samples were stored at $-20^{\circ} \mathrm{C}$ and composited periodically before drying. The extra hay was sampled repeatedly over the experimental period ( $\mathrm{n}=7$ antepartum, $\mathrm{n}=10$ postpartum) and composited per time point. The leftovers were weighed individually. Leftovers amounting to 10 to $20 \%$ of the amount offered were analyzed separately. Feed samples were dried at $65^{\circ} \mathrm{C}$ to constant weight and ground through a 1-mm screen with a centrifugal mill. Milk yield was recorded in total for $3 \mathrm{~d}$ ( $1 \mathrm{~d}$ in the tiestall followed by $2 \mathrm{~d}$ in the respiration chamber) at each milking using a mechanical milk meter (DeLaval, Sursee, Switzerland). Milk from each milking was sampled and conserved with bronopol. Once per experimental week, BW was measured with a floor scale and backfat thickness was determined by ultrasonic measurement (model Tringa Linear, Esaote/ Pie Medical, Maastricht, the Netherlands) in the sacral region according to Schröder and Staufenbiel (2006). Concomitantly, BCS was assessed on 1- to 5-point scale according to Edmonson et al. (1989). Blood was collected from a jugular vein into Vacutainer tubes (4-6 mL; Greiner Bio One, St. Gallen, Switzerland) at 0600 $\mathrm{h}$ ( $2 \mathrm{~h}$ after feeding) on d $14 \pm 6$ before parturition and on d $11 \pm 4$ after parturition. For reasons not related to the experiment, no blood could be collected from 3 cows antepartum (2 medium-responder cows and 1 high-responder cow). For the cell assays, the blood was collected into tubes containing sodium heparin for later analyses. For the other analyses, the plasma was prepared from tubes containing potassium EDTA (BHB, NEFA, and cortisol) or sodium fluoride/potassium oxalate (glucose) by centrifugation at 1,200 $\times g$ for $10 \mathrm{~min}$ at $4^{\circ} \mathrm{C}$ and stored at $-80^{\circ} \mathrm{C}$.

\section{Measurement of Gaseous Exchange}

The individual gaseous exchange was measured for 2 $\mathrm{d}$ starting at $11 \pm 5 \mathrm{~d}$ before parturition $(\mathrm{n}=13)$ and $13 \pm 3 \mathrm{~d}$ after parturition $(\mathrm{n}=14)$ equivalent to $\mathrm{d} 5$ of the 6-d experimental period. Unforeseen problems 
did not allow measurements in all 17 animals at both time points. The 2 open-circuit respiration chambers, as described in detail by Buehler and Wanner (2014), had volumes of $19.3 \mathrm{~m}^{3}$ each and were air-conditioned to maintain $18^{\circ} \mathrm{C}, 55 \%$ relative humidity, and an air pressure of $-60 \mathrm{~Pa}$ with respect to ambient pressure. Airflows were set to $700 \mathrm{~L} / \mathrm{min}$ (Promethion FG-1000 flow generators, Sable Systems Europe GmbH, Berlin, Germany). Concentrations of $\mathrm{CH}_{4}, \mathrm{CO}_{2}$, and $\mathrm{O}_{2}$ were analyzed using a gas analyzer (Promethion GA-4, Sable Systems Europe $\mathrm{GmbH}$ ). The analyzer was calibrated automatically before each measurement using pure $\mathrm{N}_{2}$ $(99.9 \%)$ and a mixed gas $\left(19.8 \% \mathrm{O}_{2}, 0.5 \% \mathrm{CO}_{2}\right.$, and $0.1 \% \mathrm{CH}_{4}$ in $\mathrm{N}_{2}$ as carrier). During the experiment, a total of 12 recovery tests of $\mathrm{O}_{2}$ and $\mathrm{CO}_{2}$ in each chamber were performed by burning propane gas. The average recovery of both chambers was $93 \%$ for $\mathrm{O}_{2}$ and $101 \%$ for $\mathrm{CO}_{2}$. The $\mathrm{O}_{2}$ and $\mathrm{CO}_{2}$ data from the experimental cows were corrected with the corresponding recovery rates obtained closest in time to the respective measurement. The 10 lowest values of $\mathrm{O}_{2}$ consumption during the night (2000 to $0400 \mathrm{~h}$ ) of both measurement days were used to determine the RMR according to Dittmann et al. (2015):

$$
\begin{gathered}
\operatorname{RMR}\left(\mathrm{kJ} / \mathrm{kg} \text { of } \mathrm{BW}^{0.75} \text { per day }\right)= \\
\mathrm{O}_{2}(\mathrm{~L}) \times 20.08(\mathrm{~kJ}) / \mathrm{BW}^{0.75}(\mathrm{~kg}) .
\end{gathered}
$$

The HP, corrected for assumed $\mathrm{CO}_{2}$ production from microbial fermentation, was calculated according to Chwalibog et al. (1996):

$$
\begin{gathered}
\mathrm{HP}(\mathrm{kJ})=16.18 \times \mathrm{O}_{2}(\mathrm{~L})+5.02 \times\left[\mathrm{CO}_{2}(\mathrm{~L})\right. \\
\left.-3 \times \mathrm{CH}_{4}(\mathrm{~L})\right]-2.17 \times \mathrm{CH}_{4}(\mathrm{~L})-5.99 \\
\times \text { urine } \mathrm{N}(50 \mathrm{~g}) .
\end{gathered}
$$

\section{Laboratory Analyses}

Feed. For analyses of DM and total ash (method 942.05; AOAC International, 1995), a thermo-gravimetric device (TGA 701, Leco Corporation, St. Joseph, MI) was used. Using a C-N analyzer (Leco-CN 2000, Leco Corporation), nitrogen and carbon contents were determined (method 968.06; AOAC International, 1995). Crude protein was calculated as $6.25 \times \mathrm{N}$. Fiber contents were analyzed with the Fibertec System M (1020 Hot Extraction; Foss, Hillerød, Denmark); NDF was analyzed using the method of Van Soest et al. (1991), and $\mathrm{ADF}$ and ADL were analyzed using method 973.18 of AOAC International (1995). For NDF analysis, heatstable $\alpha$-amylase was used, but no sodium sulfite. The ADL was analyzed sequentially after the ADF step by incubation in sulfuric acid (72\%) for $3 \mathrm{~h}$. A calorimeter (C7000, IKA-Werke GmbH and Co. KG, Staufen, Germany) was applied for quantifying gross energy. Ether extract was assessed with a Soxhlet extraction system (Extraktionsapparatur B-811, Büchi Labortechnik AG, Flawil, Switzerland; method 963.15, AOAC International, 1995).

Milk. The bronopol-conserved milk was analyzed for contents of fat, protein, and lactose as well as SCC using a Fourier-transform infrared spectrophotometer (MilkoScan FT6000, Foss) at the Swiss routine milk analysis laboratory (Suisselab AG, Zollikofen, Switzerland). The fat:protein ratio of milk was calculated as an indicator of ketosis (Buttchereit et al., 2010). The ECM was calculated based on Agroscope (2019):

$$
\begin{gathered}
\mathrm{ECM}(\mathrm{kg})=\text { milk }(\mathrm{kg}) \times[0.39 \times \text { fat }(\%)+0.24 \\
\times \text { protein }(\%)+0.17 \times \text { lactose }(\%)] / 3.14 .
\end{gathered}
$$

Blood. Plasma was analyzed for glucose, NEFA, and BHB with an automated analyzer (Cobas Mira 2, Hoffmann-La Roche, Basel, Switzerland) using commercial kits (Randox Laboratories Ltd., Schwyz, Switzerland) as described by van Dorland et al. (2009) and Kreipe et al. (2011). Cortisol in plasma was analyzed with a RIA according to Thun et al. (1981).

PBMC Activation and Proliferation Assay. The PBMC were isolated by density-gradient centrifugation and resuspended with RPMI 1640 medium (Merck AG, Zug, Switzerland) with additives (2 $\mathrm{mM}$ L-glutamine, $10 \mathrm{~m} M$ HEPES, 10\% fetal bovine serum). Cell number and viability were determined using an automatic cell counter (Eve, NanoenTek, Seoul, Korea). The PBMC activation was assessed by measuring $\mathrm{O}_{2}$ consumption rate (OCR) for $24 \mathrm{~h}$ as a measure of ATP production (Schwarm et al., 2013). This activation assay was conducted in the presence or absence of the $\mathrm{T}$ cell mitogen phytohemagglutinin $\mathrm{L}(4 \mu \mathrm{g} / \mathrm{mL}$; Merck AG). Isolated cell suspensions were seeded in quadruplicate per treatment onto fluorophore-coated 96-well Oxoplates (PreSens, Regensburg, Germany) after adjusting cell concentration to $2 \times 10^{6}$ cells $/ \mathrm{mL}$. The PBMC were incubated in humidified air with $5 \%$ $\mathrm{CO}_{2}$ at $39^{\circ} \mathrm{C}$ for $24 \mathrm{~h}$. Fluorescence was detected with a microplate reader (Cytation $3 \mathrm{M}$, Biotek, Lucerne, Switzerland) from the bottom side in a dual kinetic mode $(540 / 650 \mathrm{~nm}$ and 540/590 nm). Fluorescence intensity was converted into oxygen concentration following the instruction manual of PreSens. The oxygen partial pressure in percent air saturation was used to adjust oxygen concentration $\left(\mathrm{cO}_{2} ; \mu M\right)$ by multiplication with 1.93 (PreSens template; www.presens.de/ support/download-center/tools-utilities.html) for $39^{\circ} \mathrm{C}$ 
and $965 \mathrm{hPa}$. The OCR (fmol/min) in the well was calculated according to Wang et al. (2005) using $0.71 \mathrm{~cm}$ as diffusion path length and $0.35 \mathrm{~cm}^{2}$ as surface area exposed to the atmosphere. The OCR was scaled to cell number, which was assessed from plates incubated for $24 \mathrm{~h}$ in parallel. The relative activation index (AIx) was calculated using OCR $\left[\mathrm{nmol} /\left(\min \times 10^{7}\right.\right.$ cells $\left.)\right]$ as

$$
\mathrm{AIx}=\mathrm{OCR}_{\text {presence of mitogen }} / \mathrm{OCR}_{\text {absence of mitogen }} .
$$

The PBMC proliferation in the presence or absence of the mitogen phytohemagglutinin $\mathrm{L}$ was assessed using 3-[4,5-dimethyldiazol-2-yl]-2,5 diphenyl tetrazolium bromide (MTT; Sigma-Aldrich, Buchs, Switzerland) as described by Meese et al. (2018). The PBMC incubation procedure was as described for activation except that the cell culture plate was conventional. After 72 $\mathrm{h}$, cells were treated with MTT and incubated for $4 \mathrm{~h}$ and then overnight after application of SDS (SigmaAldrich). The optical density (OD) was measured with the same microplate reader with test and reference wavelengths of 550 and $690 \mathrm{~nm}$, respectively. The PI was calculated as

$$
\mathrm{PI}=\mathrm{OD}_{\text {presence of mitogen }} / \mathrm{OD}_{\text {absence of mitogen }} .
$$

Flow Cytometry. The proportion of leukocyte subsets (granulocytes, lymphocytes, and monocytes) in aliquots of blood and isolated PBMC as well as the cell cycle status $\left(\mathrm{G}_{0}, \mathrm{G}_{1}\right.$, synthesis, mitosis) of PBMC were assessed with a Cytomics flow cytometer (FC500 MPL; Beckman Coulter, Nyon, Switzerland) equipped with 488- and 635-nm argon lasers. Erythrocytes in the blood aliquots were lysed using VersaLyse (Beckman Coulter). Blood cells and PBMC were then preserved in $4 \%$ paraformaldehyde at $4^{\circ} \mathrm{C}$; the $\mathrm{PBMC}$ were also preserved in $70 \%$ alcohol and stored at $-20^{\circ} \mathrm{C}$. Cells $(7,000-20,000)$ were gated based on side (proportional to cellular granularity) and forward (proportional to cell size) scatter characteristics of each population and differentiated based on Jones et al. (2007) using the dyes fluorescein isothiocyanate-peanut agglutinin and propidium iodide (Sigma-Aldrich).

\section{Statistical Evaluation}

Repeated-measurement ANOVA was performed by applying the Mixed procedure of SAS (version 9.3; SAS Institute Inc., Cary, NC). Time (before or after calving), animal group (low, medium, or high responders), and the animal group $\times$ time interaction were considered as fixed effects. Individual cow was considered as experimental unit. Inclusion of lactation number as random factor in the model did not change effects and associated interactions of immunological traits (data not shown). Therefore, lactation number was not included in the final model. Multiple comparisons among means were performed using the Tukey-Kramer test. Differences were considered significant at $P \leq 0.05$ and a trend at $P \leq 0.10$. Data are presented as least squares means \pm standard error of the mean unless otherwise stated. Spearman correlation coefficients between immunological traits and traits of energy metabolism and their significance were calculated using the Corr procedure of SAS.

\section{RESULTS}

\section{Feed Intake, Body Condition, and Performance}

Dry matter intake increased $(P<0.001)$ and BCS $(P<0.05)$ and BW $(P<0.001)$ decreased after calving (Table 2). Backfat thickness did not change $(P>$ $0.10)$ with time. There were no significant $(P>0.10)$ interactions between animal group (low, medium, or high responders) and time (before or after calving) and no effect $(P>0.10)$ of group in any of these variables.

We observed no differences $(P>0.10)$ between groups in ECM yield $(42.3 \pm 1.01 \mathrm{~kg})$, milk production efficiency $(6.56 \pm 0.196 \mathrm{~kg}$ of ECM/100 kg of BW), and feed conversion efficiency $(1.94 \pm 0.063 \mathrm{~kg}$ of ECM/ $\mathrm{kg}$ of DMI). The milk fat:protein ratio and the SCC were not different $(P>0.10)$ between the groups, with on average $1.18 \pm 0.038$ and $157,000 \pm 97.5$ cells $/ \mathrm{mL}$, respectively. No significant $(P>0.10)$ correlations occurred between immunological traits and DMI, BW, BCS, backfat thickness, or ECM variables except for a positive correlation between AIx and DMI $(\mathrm{r}=0.47$, $P<0.05)$.

\section{Metabolic Rate, HP, and Methane Production}

The RMR and HP increased $(P<0.001)$ to $1.30-$ fold values from antepartum to postpartum (Table 2), but there were no significant $(P>0.10)$ interactions between group (low, medium, or high responder) and time (before or after calving) and no effects $(P>0.10)$ of group. Daily methane production tended to differ $(P<0.10)$ between groups and increased after calving $(P<0.05)$ in all groups (Figure 1B). This increase was particularly great in medium responders (1.8-fold increase), resulting in a trend $(P<0.10)$ for a group $\times$ time interaction. After calving, methane yield (per unit of DMI and per unit of gross energy intake) decreased $(P<0.01)$. However, neither group $\times$ time interactions $(P>0.10)$ nor group effects $(P>0.10)$ were observed (Table 1). Methane emission intensity (per $100 \mathrm{~kg}$ of BW) tended to differ $(P<0.10)$ between groups and 
Table 2. Metabolic and immunological traits (LSM) in dry and lactating cows ${ }^{1}$

\begin{tabular}{|c|c|c|c|c|}
\hline Item & \multicolumn{2}{|c|}{ Period } & SEM & $P$-value \\
\hline DMI (kg) & 11.4 & 22.0 & 0.591 & $<0.001$ \\
\hline $\mathrm{BCS}$ & 2.95 & 2.75 & 0.118 & 0.025 \\
\hline Backfat thickness (cm) & 0.91 & 0.79 & 0.102 & 0.187 \\
\hline Resting metabolic rate $\left(\mathrm{kJ} / \mathrm{kg}\right.$ of $\mathrm{BW}^{0.75}$ per day) & 645 & 865 & 31.9 & $<0.001$ \\
\hline $\mathrm{g} / \mathrm{kg}$ of DMI & 21.1 & 17.6 & 0.885 & 0.008 \\
\hline$\%$ of gross energy & 6.43 & 4.74 & 0.273 & $<0.001$ \\
\hline \multicolumn{5}{|l|}{ Plasma concentration } \\
\hline Glucose $(\mathrm{m} M)$ & 3.37 & 2.93 & 0.076 & $<0.001$ \\
\hline Nonesterified fatty acids $(\mu M)$ & 216 & 477 & 101 & 0.109 \\
\hline $\mathrm{BHB}(\mu M)$ & 380 & 834 & 193 & 0.097 \\
\hline Cortisol (ng/mL) & 4.25 & 2.95 & 0.613 & 0.046 \\
\hline \multicolumn{5}{|l|}{ Blood leukocyte proportion (\% of total leukocytes) } \\
\hline \multicolumn{5}{|l|}{$\mathrm{PBMC}^{2}$ subsets ( $\%$ of isolated PBMC) } \\
\hline Lymphocytes & 88.3 & 86.7 & 1.30 & 0.304 \\
\hline Monocytes & 11.7 & 13.3 & 1.30 & 0.304 \\
\hline \multicolumn{5}{|l|}{ Cell cycle $^{3}$ status ( $\%$ of isolated PBMC) } \\
\hline $\mathrm{G}_{0}$ phase & 80.5 & 81.5 & 2.93 & 0.650 \\
\hline $\mathrm{G}_{1}$ phase & 3.69 & 1.67 & 0.85 & 0.100 \\
\hline Synthesis phase & 9.13 & 10.7 & 1.73 & 0.364 \\
\hline Mitosis phase & 6.75 & 5.76 & 1.58 & 0.628 \\
\hline \multicolumn{5}{|l|}{$\mathrm{PBMC}$ reaction after $24 \mathrm{~h}$ of incubation } \\
\hline $\mathrm{OCR}^{4}$ unstimulated & 2.61 & 2.81 & 0.157 & 0.332 \\
\hline $\mathrm{OD}^{5}$ unstimulated & 0.640 & 0.558 & 0.056 & 0.176 \\
\hline
\end{tabular}

${ }^{1}$ Values of dry and lactating cows are given as the pooled mean of low-, medium-, and high-responder cows because the interaction of group (low, medium, or high) and state of lactation (dry or early lactating) was not significant.

${ }^{2}$ Peripheral blood mononuclear cells.

${ }^{3} \mathrm{G}_{0}$ phase $=$ quiescent cells; $\mathrm{G}_{1}$ phase $=$ cell growth (RNA and protein syntheses); synthesis phase = DNA replication; mitosis phase $=$ cell division.

${ }^{4}$ Oxygen consumption rate $\left(\mathrm{nmol} / \mathrm{min} \times 10^{7}\right.$ cells $)$ of PBMC incubated for $24 \mathrm{~h}$ without the mitogen phytohemagglutinin.

${ }^{5}$ Optical density of PBMC incubated for $72 \mathrm{~h}$ without the mitogen phytohemagglutinin.

increased $(P<0.01)$ postpartum in all groups (Figure $1 \mathrm{C})$. The increase was greatest in the medium responders (2.0-fold increase) and smallest in low responders (group $\times$ time interaction, $P<0.10)$. Methane emission intensity (per $\mathrm{kg}$ of ECM) was smaller $(P<0.05)$ in low responders than in medium and high responders (Figure 1D). Among the immunological traits, AIx was correlated $(P<0.05)$ with RMR $(\mathrm{r}=0.42)$, HP $(\mathrm{r}=0.44)$, daily methane production $(\mathrm{r}=0.62)$, and methane emission intensity (per $100 \mathrm{~kg}$ of $\mathrm{BW}, \mathrm{r}=$ $0.63)$, and PI was correlated $(P<0.05)$ with methane emission intensity (per $\mathrm{kg}$ of ECM, $\mathrm{r}=0.72$; per $100 \mathrm{~kg}$ of $\mathrm{BW}, \mathrm{r}=0.63)$.

\section{Blood Metabolites and Hormones}

Compared with before calving, concentrations of glucose and cortisol decreased after calving $(P<0.05)$, and we observed a trend $(P<0.10)$ for an increase of
BHB concentration and no difference $(P>0.10)$ in NEFA concentrations (Table 2). There were no interactions $(P>0.10)$ between group (low, medium, or high responder) and time (before or after calving) and no group effects $(P>0.10)$ in any of these variables. No significant $(P>0.10)$ correlations occurred between immunological traits and blood metabolites and hormones.

\section{Proportions of Leukocyte Subsets, Cell Cycle Status, and In Vitro Reactivity of PBMC}

Compared with the dry period, we observed a decrease $(P<0.05)$ in granulocyte proportions and an increase in lymphocyte $(P<0.05)$ and monocyte $(P<$ $0.10)$ proportions in early lactation (Table 2 ), but no interactions $(P>0.10)$ between group (low, medium, or high responder) and time (before and after calving) and no group effects $(P>0.10)$ were found. In PBMC, 
there were no effects $(P>0.10)$ of group or time and no $(P>0.10)$ group $\times$ time interactions in the proportions of lymphocytes and monocytes or in the proportions of cells in $\mathrm{G}_{0}, \mathrm{G}_{1}$, synthesis, and mitosis phases of the cell cycle. There were no time differences $(P>0.10)$ in the basal oxygen consumption of PBMC cultured for $24 \mathrm{~h}$ without mitogen or in the basal MTT-reducing activity of PBMC cultured for $72 \mathrm{~h}$ without mitogen. Groups slightly differed $(P=0.094)$ in the basal OCR of PBMC, but no interaction $(P>0.10)$ between group and time was found. We observed a group $\times$ time interaction $(P=0.097)$ in the basal MTT-reducing activity (OD of unstimulated PBMC) but no effect $(P>0.10)$ of group. There were a group $\times$ time interaction $(P<$ $0.05)$ and effects of group $(P<0.10)$ and time $(P<$ 0.05 ) in PI (Figure 1A). The interaction resulted from different responses of responder groups in PI ante- and postpartum. However, we revealed no $(P>0.10)$ group $\times$ time interaction, group, or time effects for AIx (Figure 1E). No significant $(P>0.10)$ correlations occurred between the PBMC characteristics and traits of energy metabolism.

\section{DISCUSSION}

\section{In Vitro PBMC Activation and Proliferation and In Vivo Leukocyte Status}

In the present study, animal groups (low, medium, or high responders) did not differ in the proportions of leukocyte subgroups in the blood (in vivo) and in isolated PBMC before incubation (in vitro). The differences in proliferative responsiveness found in vitro are expected to reflect the capability to respond to an antigen in vivo. However, it should be noted that the immune response under in vivo conditions is modulated by metabolites and endocrine factors, which is discussed in the following section. The observed lack of responder group differences in the proportion of the cell cycle phases $G_{0}, G_{1}$, synthesis, and mitosis of the isolated PBMC (before incubation) implies that the groups did not differ in their in vivo stages of preactivation and preproliferation before the in vitro incubation started.

The level of AIx mostly reflected that of the basal OCR (OCR unstimulated). Different from that, the level of PI was inversely changing over time compared with the basal MTT-reducing activity (OD unstimulated). From these observations, we concluded that the PI of high responders was particularly high postpartum because of a comparatively low basal MTT-reducing activity.

The observation of a positive correlation between PBMC activation and DMI supports the linkage of the nutritional status of an animal and the capability to start an immune response (Sordillo, 2016). However, the cows grouped by low, medium, and high PBMC proliferation postpartum did not differ in PBMC activation, which indicates that the cell cycle was completed to a smaller extent in the PBMC of the low-responder cows compared with the high-responder cows. Despite the optimized conditions in the in vitro incubation in complete medium, the PBMC of low responders seem to have been imprinted in vivo in an energetically less favorable condition, limiting their utilization of the surrounding nutrients. Different from that, though not completely comparable with the present study, Catalani et al. (2013) categorized dairy cows into low, medium, and high responders based on the average lymphoproliferative response to LPS over 7 peripartal weeks. They found that high-responder cows were the least susceptible to infectious diseases.

\section{Relationship Between Performance and Efficiency with Immune Response During Transition}

The onset of the lactation in high-yielding dairy cows is a critical time concerning nutrient supply. It may result in a massive increase in plasma concentrations of BHB and NEFA (Weber et al., 2013) and loss of BW and BCS, especially in previously overconditioned cows. However, this was not the case in the cows used in the present study. The increase in DMI from $11 \mathrm{~kg} / \mathrm{d}$ in the dry period to $22 \mathrm{~kg} / \mathrm{d}$ in early lactation was steep and obviously was widely sufficient to support a yield of $42 \mathrm{~kg}$ of $\mathrm{ECM} / \mathrm{d}$ from the beginning. As a consequence, the loss of BCS was only from 3.0 to 2.75 . Most of the $61 \mathrm{~kg}$ of $\mathrm{BW}$ loss could be attributed to calf weight, and we observed no significant change in backfat thickness. All of this coincides with the comparably small peripartal increase in plasma BHB and the lack of difference in plasma NEFA. In accordance with this, the fat:protein ratio in milk was only 1.17 , which is clearly below the threshold of 1.5 , which would indicate high lipolysis and the risk of developing ketosis (Buttchereit et al., 2010).

In the present study, the immune response rank was not related to differences in energy availability as assessed by feed intake, body reserve mobilization (estimated via changes in BCS and backfat thickness), and milk yield. This is in accordance with Stoop et al. (2016), who found no difference in milk yield among low-, medium-, and high-responder cows. At unchanged DMI and ECM, feed conversion efficiency (ECM per unit of DMI) was similar among groups and thus did not coincide with the differences found in lymphoproliferative response postpartum. The decrease in plasma glucose concentrations postpartum was also similar among groups. The plasma BHB serves as fuel in acute 
inflammations (Zarrin et al., 2014). However, high concentrations of NEFA (Lacetera et al., 2004) and ketone bodies (Targowski and Klucinski, 1983; Meese et al., 2018) would likely suppress the proliferation of bovine PBMC. However, at moderate concentrations, as was the case in the present study, these metabolites can be used as an energy source by bovine PBMC (Fox et al., 2005; Schulz et al., 2015; Wang et al., 2018). Around parturition, plasma glucocorticoid concentrations (e.g., that of cortisol) are typically elevated due to metabolic stress, and this can reduce $\mathrm{T}$ cell proliferation (Roth, 1985). However, in the present study, cortisol concentrations in plasma decreased peripartal, similarly to that reported by Weber et al. (2013) for cows with low liver fat contents. Bloom et al. (1979) reported that in vivo glucocorticoid treatment depleted the number of circulating lymphocytes, which corresponds well with our observation of smaller proportions of lymphocytes antepartum where cortisol concentrations were comparatively higher. Still, it is likely that a more pronounced energy deficiency at the beginning of lactation would have led to greater differences in performance and plasma metabolite concentrations between responder groups.

\section{Relationship Between Metabolic Rate and Energy Losses Through Heat and Methane with Immune Response During Transition}

In the present study, the generally higher metabolic energy turnover in response to milk formation was reflected in higher RMR and HP postpartum compared with antepartum. We anticipated that low-responder cows with reduced energy availability (to support immunologic activity) might display smaller RMR and HP compared with high-responder cows. However, groups did not differ in RMR and HP. In experiments inducing fever in sheep, RMR was increased by $28 \%$ (Fewell et al., 1991). In line with that, a positive correlation of PBMC activation with RMR and HP was observed. However, in the clinically healthy cows of the present study with their rather good supply with dietary energy, differences in PBMC proliferation might have been too small to lead to clear group variations in RMR and HP. In contrast to RMR, which is based on oxygen consumption of the cows, state of lactation did not affect the in vitro oxygen consumption (reflecting ATP production) of the unstimulated PBMC, suggesting that the energy partitioned by the cows toward immunological maintenance was the same ante- and postpartum.

We did not expect the observed difference between responder groups in the production of enteric methane. Methane formation is linearly related to DMI (Niu et al., 2018) and thus largely increased when DMI doubled postpartum. However, the increase in methane was lower than the increase in DMI. Therefore, the methane yield (per unit of DMI or gross energy intake) concomitantly decreased. The low-responder cows were found to exhibit a smaller methane emission intensity per unit of BW and ECM. Consistent with that, there was a positive correlation of PBMC activation and proliferation with methane emission intensity. Retrospectively, the experimental set-up did not allow us to obtain information about ruminal and total-tract nutrient degradation and digestion apart from methane formation. The lower methane emission intensity of the low-responder cows may indicate a generally lower fermentation intensity, possibly because the rumen and the microorganisms in the rumen of low-responder cows do not achieve a similar degree of adaptation to the DMI increase as that of medium- and high-responder cows. In early lactation, low-responder cows might then gain comparably less digestive energy to sustain immune response, particularly the shift from activation to proliferation. However, it cannot be excluded that fermentation was simply shifted from acetate and methane formation to propionate (a glucogenic shortchain fatty acid) synthesis in the rumen, thus even improving energy availability to the mammary gland, but apparently not to the immune system.

\section{CONCLUSIONS}

Cows clearly differed in the postpartum immune response based on mitogen-induced lymphocyte proliferation in vitro, although no differences were observed in performance and metabolic modifications between cows at the onset of the lactation. The concomitant differences in enteric methane emissions may suggest that low-immune responders could still be at a disadvantage compared with medium- or high-responder cows in metabolic energy supply. They thus would be forced to favor milk production over the maintenance of a fully operative immune system. If so, the selection of cows that emit low levels of methane for environmental reasons could favor animals with a greater disease susceptibility. Further studies comprising early-lactating cows with a more critical energy status and an in-depth investigation of ruminal digestion will have to confirm this finding.

\section{ACKNOWLEDGMENTS}

The authors are grateful to C. Kunz, M. Mergani, T. Menzi, and C. Morel (ETH Zurich, Zurich, Switzerland) for assistance in the laboratory and to S. Rinderknecht, M. Hunziker, and H. Renfer (AgroVet-Strickhof, Lindau, 
Switzerland) for their support during the experiment. Special thanks to P. Stirnemann (ETH Zurich, Zurich, Switzerland) for his assistance with the cell culture assays; J. Bérard, M. Terranova (ETH Zurich, Zurich, Switzerland), and T. Ådnøy (NMBU, Ås, Norway) for their statistical advice; M. Siuda (Vetsuisse Faculty, University of Zurich, Zurich, Switzerland) for his help with flow cytometry protocols; M. Egli (ETH Zurich, Zurich, Switzerland) for calculation of well dimension with computer-aided design inventor and construction of trough separators; and D. Sauvant (AgroParisTech, Paris, France) for his valuable comments. The project was supported by the German Research Foundation (Bonn, SCHW 1485/3-1). The authors have not stated any conflicts of interest.

\section{REFERENCES}

Agroscope. 2019. Feeding Recommendations and Nutrient Tables for Ruminants (in German). Accessed Jul. 5, 2019. https:// www.agroscope.admin.ch/agroscope/de/home/services/dienste/ futtermittel/fuetterungsempfehlungen-wiederkaeuer.html.

Amadori, M., J. F. Soares-Filipe, F. Riva, A. Vitali, J. Ruggeri, and N. Lacetera. 2018. Characterization of the blastogenic response to LPS of bovine peripheral blood mononuclear cells. PLoS One 13:e0204827. https://doi.org/10.1371/journal.pone.0204827.

AOAC International. 1995. Official Methods of Analysis. Association of Official Analytical Chemists, Arlington, VA.

Bloom, J. C., S. J. Kenyon, and G. T. Gabuzda. 1979. Glucocorticoid effects on peripheral blood lymphocytes in cows infected with bovine leukemia virus. Blood 53:899-912. https://doi.org/10.1182/ blood.V53.5.899.899.

Buehler, K., and M. Wanner. 2014. Metabolic Centre of the University of Zurich and ETH Zurich (under construction). Pages 89-106 in Technical Manual on Respiration Chamber Designs. C. Pinares and G. Waghorn, ed. Ministry of Agriculture and Forestry, Wellington, New Zealand.

Burton, J. L., B. A. Mallard, and D. N. Mowat. 1993. Effects of supplemental chromium on immune-responses of periparturient and early lactation dairy cows. J. Anim. Sci. 71:1532-1539. https://doi .org/10.2527/1993.7161532x.

Buttchereit, N., E. Stamer, W. Junge, and G. Thaller. 2010. Evaluation of five lactation curve models fitted for fat:protein ratio of milk and daily energy balance. J. Dairy Sci. 93:1702-1712. https:/ /doi.org/10.3168/jds.2009-2198.

Catalani, E., M. Amadori, A. Vitali, and N. Lacetera. 2013. Lymphoproliferative response to lipopolysaccharide and incidence of infections in periparturient dairy cows. J. Dairy Sci. 96:7077-7081. https://doi.org/10.3168/jds.2013-6854.

Chwalibog, A., K. Jensen, and G. Thorbek. 1996. Oxidation of nutrients in bull calves treated with beta-adrenergic agonists. Arch. Tierernahr. 49:255-261.

Dang, A. K., S. Prasad, K. De, S. Pal, J. Mukherjee, I. V. Sandeep, G. Mutoni, M. M. Pathan, M. Jamwal, S. Kapila, R. Kapila, H. Kaur, S. Dixit, A. K. Mohanty, and B. S. Prakash. 2013. Effect of supplementation of vitamin E, copper and zinc on the in vitro phagocytic activity and lymphocyte proliferation index of peripartum Sahiwal (Bos indicus) cows. J. Anim. Physiol. Anim. Nutr. (Berl.) 97:315321. https://doi.org/10.1111/j.1439-0396.2011.01272.x.

Dittmann, M. T., C. Hebel, A. Arif, M. Kreuzer, and M. Clauss. 2015. Metabolic rates of three gazelle species (Nanger soemmerringii, Gazella gazella, Gazella spekei) adapted to arid habitats. Mamm. Biol. 80:390-394. https://doi.org/10.1016/j.mambio.2015.05.008.

Edmonson, A. J., I. J. Lean, L. D. Weaver, T. Farver, and G. Webster. 1989. A body condition scoring chart for Holstein dairy- cows. J. Dairy Sci. 72:68-78. https://doi.org/10.3168/jds.S0022 -0302(89)79081-0.

Fewell, J. E., F. Ricciuti, C. S. Kondo, and V. Dascalu. 1991. Fever in young lambs: Temperature, metabolic and cardiorespiratory responses to a small dose of bacterial pyrogen. J. Dev. Physiol. 15:229-235.

Fox, C. J., P. S. Hammerman, and C. B. Thompson. 2005. Fuel feeds function: Energy metabolism and the T-cell response. Nat. Rev. Immunol. 5:844-852. https://doi.org/10.1038/nri1710.

Gross, J., H. A. van Dorland, R. M. Bruckmaier, and F. J. Schwarz. 2011. Performance and metabolic profile of dairy cows during a lactational and deliberately induced negative energy balance with subsequent realimentation. J. Dairy Sci. 94:1820-1830. https://doi .org/10.3168/jds.2010-3707.

Jones, R. G., D. R. Plas, S. Kubek, M. Buzzai, J. Mu, Y. Xu, M. J. Birnbaum, and C. B. Thompson. 2005. AMP-activated protein kinase induces a p53-dependent metabolic checkpoint. Mol. Cell 18:283-293. https://doi.org/10.1016/j.molcel.2005.03.027.

Jones, S., N. Horwood, A. Cope, and F. Dazzi. 2007. The antiproliferative effect of mesenchymal stem cells is a fundamental property shared by all stromal cells. J. Immunol. 179:2824-2831. https:// doi.org/10.4049/jimmunol.179.5.2824.

Kashiwazaki, Y., Y. Maede, and S. Namioka. 1985. Transformation of bovine peripheral blood lymphocytes in the perinatal period. Nihon Juigaku Zasshi 47:337-339. https://doi.org/10.1292/jvms1939 .47 .337 .

Kreipe, L., M. C. Vernay, A. Oppliger, O. Wellnitz, R. M. Bruckmaier, and H. A. van Dorland. 2011. Induced hypoglycemia for 48 hours indicates differential glucose and insulin effects on liver metabolism in dairy cows. J. Dairy Sci. 94:5435-5448. https://doi.org/10 $.3168 /$ jds.2011-4208.

Lacetera, N., D. Scalia, U. Bernabucci, B. Ronchi, D. Pirazzi, and A. Nardone. 2005. Lymphocyte functions in overconditioned cows around parturition. J. Dairy Sci. 88:2010-2016. https://doi.org/10 .3168/jds.S0022-0302(05)72877-0.

Lacetera, N., D. Scalia, O. Franci, U. Bernabucci, B. Ronchi, and A. Nardone. 2004. Effects of nonesterified fatty acids on lymphocyte function in dairy heifers. J. Dairy Sci. 87:1012-1014. https://doi .org/10.3168/jds.S0022-0302(04)73246-4.

Mallard, B. A., J. C. Dekkers, M. J. Ireland, K. E. Leslie, S. Sharif, C. Lacey Vankampen, L. Wagter, and B. N. Wilkie. 1998. Alteration in immune responsiveness during the peripartum period and its ramification on dairy cow and calf health. J. Dairy Sci. 81:585595. https://doi.org/10.3168/jds.S0022-0302(98)75612-7.

Meese, S., U. Gimsa, M. Röntgen, J. M. Weitzel, A. Tuchscherer, C. Miersch, A. Vernunft, T. Viergutz, M. Kreuzer, and A. Schwarm. 2018. Effect of immune modulators and lactation number on in vitro proliferation of lymphocytes from non-pregnant dairy heifers and cows. Can. J. Anim. Sci. 98:898-901. https://doi.org/10.1139/ cjas-2017-0143.

Niu, M., E. Kebreab, A. N. Hristov, J. Oh, C. Arndt, A. Bannink, A. R. Bayat, A. F. Brito, T. Boland, D. Casper, L. A. Crompton, J. Dijkstra, M. A. Eugène, P. C. Garnsworthy, N. Haque, A. L. F. Hellwing, P. Huhtanen, M. Kreuzer, B. Kuhla, P. Lund, J. Madsen, C. Martin, S. C. McClelland, M. McGee, P. Moate, S. Muetzel, C. Muñoz, P. O'Kiely, N. Peiren, C. K. Reynolds, A. Schwarm, K. J. Shingfield, T. M. Storlien, M. R. Weisbjerg, D. R. Yáñez-Ruiz, and Z. Yu. 2018. Prediction of enteric methane production, yield and intensity in dairy cattle using an intercontinental database. Glob. Chang. Biol. 24:3368-3389. https://doi.org/10.1111/gcb.14094.

Rathmell, J. C., M. G. Vander Heiden, M. H. Harris, K. A. Frauwirth, and C. B. Thompson. 2000. In the absence of extrinsic signals, nutrient utilization by lymphocytes is insufficient to maintain either cell size or viability. Mol. Cell 6:683-692. https://doi.org/10.1016/ S1097-2765(00)00066-6.

Roth, J. 1985. Cortisol as mediator of stress-associated immunosuppression in cattle. Pages 225-243 in Animal Stress. G. Moberg, ed. American Physiological Society, Bethesda, MD.

Schroder, U. J., and R. Staufenbiel. 2006. Methods to determine body fat reserves in the dairy cow with special regard to ultrasono- 
graphic measurement of backfat thickness. J. Dairy Sci. 89:1-14. https://doi.org/10.3168/jds.S0022-0302(06)72064-1.

Schulz, K., J. Frahm, S. Kersten, U. Meyer, D. Reiche, H. Sauerwein, and S. Dänicke. 2015. Effects of elevated parameters of subclinical ketosis on the immune system of dairy cows: In vivo and in vitro results. Arch. Anim. Nutr. 69:113-127. https://doi.org/10.1080/ 1745039X.2015.1013666.

Schwarm, A., T. Viergutz, B. Kuhla, H. M. Hammon, and M. Schweigel-Röntgen. 2013. Fuel feeds function: Energy balance and bovine peripheral blood mononuclear cell activation. Comp. Biochem. Physiol. A Mol. Integr. Physiol. 164:101-110. https://doi.org/10 .1016/j.cbpa.2012.10.009.

Sordillo, L. M. 2016. Nutritional strategies to optimize dairy cattle immunity. J. Dairy Sci. 99:4967-4982. https://doi.org/10.3168/jds .2015-10354.

Stoop, C. L., K. A. Thompson-Crispi, S. L. Cartwright, and B. A. Mallard. 2016. Variation in production parameters among Canadian Holstein cows classified as high, average, and low immune responders. J. Dairy Sci. 99:4870-4874. https://doi.org/10.3168/ jds.2015-10145.

Straub, R. H., M. Cutolo, F. Buttgereit, and G. Pongratz. 2010. Energy regulation and neuroendocrine-immune control in chronic inflammatory diseases. J. Intern. Med. 267:543-560. https://doi.org/ 10.1111/j.1365-2796.2010.02218.x.

Targowski, S. P., and W. Klucinski. 1983. Reduction in mitogenic response of bovine lymphocytes by ketone bodies. Am. J. Vet. Res. 44:828-830.

Thun, R., E. Eggenberger, K. Zerobin, T. Luscher, and W. Vetter. 1981. Twenty-four hour secretory pattern of cortisol in the bull: Evidence of episodic secretion and circadian rhythm. Endocrinology 109:2208-2212. https://doi.org/10.1210/endo-109-6-2208.

van Dorland, H. A., S. Richter, I. Morel, M. G. Doherr, N. Castro, and R. M. Bruckmaier. 2009. Variation in hepatic regulation of metabolism during the dry period and in early lactation in dairy cows. J. Dairy Sci. 92:1924-1940. https://doi.org/10.3168/jds.2008-1454.

Van Soest, P. J., J. B. Robertson, and B. A. Lewis. 1991. Methods for dietary fiber, neutral detergent fiber, and nonstarch polysaccha- rides in relation to animal nutrition. J. Dairy Sci. 74:3583-3597. https://doi.org/10.3168/jds.S0022-0302(91)78551-2.

Wang, S., S. Meese, S. E. Ulbrich, H. Bollwein, M. Röntgen, U. Gimsa, and A. Schwarm. 2018. Effect of immune modulators on in vitro activation and proliferation of peripheral blood mononuclear cells from multiparous Holstein cows peripartum. J. Anim. Physiol. Anim. Nutr. (Berl.) 102:1515-1520. https://doi.org/10.1111/jpn .12972

Wang, W., L. Upshaw, D. M. Strong, R. P. Robertson, and J. Reems. 2005. Increased oxygen consumption rates in response to high glucose detected by a novel oxygen biosensor system in non-human primate and human islets. J. Endocrinol. 185:445-455. https://doi .org/10.1677/joe.1.06092.

Weber, C., C. Hametner, A. Tuchscherer, B. Losand, E. Kanitz, W. Otten, S. P. Singh, R. M. Bruckmaier, F. Becker, W. Kanitz, and H. M. Hammon. 2013. Variation in fat mobilization during early lactation differently affects feed intake, body condition, and lipid and glucose metabolism in high-yielding dairy cows. J. Dairy Sci. 96:165-180. https://doi.org/10.3168/jds.2012-5574.

Zarrin, M., O. Wellnitz, H. A. van Dorland, J. J. Gross, and R. M. Bruckmaier. 2014. Hyperketonemia during lipopolysaccharide-induced mastitis affects systemic and local intramammary metabolism in dairy cows. J. Dairy Sci. 97:3531-3541. https://doi.org/10 $.3168 /$ jds.2013-7480.

\section{ORCIDS}

S. Meese ำ https://orcid.org/0000-0002-0832-3184

R. Bruckmaier () https://orcid.org/0000-0002-9374-5890

O. Wellnitz @ https://orcid.org/0000-0002-5817-3428

M. Kreuzer 으 https://orcid.org/0000-0002-9978-1171

M. Röntgen (ํ) https://orcid.org/0000-0002-1159-4663

U. Gimsa (ํ) https://orcid.org/0000-0003-2248-5793

A. Schwarm (ㄴ) https://orcid.org/0000-0002-5750-2111 